\title{
Qualidade de vida no trabalho e valorização do profissional do serviço de geriatria em um hospital do município de São Paulo
}

\section{RESUMO}

O objetivo do estudo foi analisar a qualidade de vida no trabalho dos profissionais do setor de geriatria em um hospital no município de São Paulo. Trata-se de um estudo descritivo, transversal, qualitativo, realizado no setor de Geriatria. A amostra foi composta de 31 trabalhadores (enfermeiros, médicos, nutricionistas, fonoaudiólogos, Assistente Social, psicólogos, Administração e Farmacêuticos) que participaram do estudo de forma voluntária, divididos em grupos. Foi aplicado o Instrumento de Avaliação SF-36. O método para a análise do grupo foi o DSC- Técnica que permite analisar diferenças e semelhanças da visão do pensamento coletivo. Os domínios do SF-36 analisados foram o funcionamento físico, limitação física e emocional, funcionamento social, saúde mental, dor, vitalidade, e percepções da saúde geral. Os resultados da análise DSC possibilitou evidenciar que os funcionários possuem uma percepção positiva das diversas variáveis relacionadas à dimensão do atendimento ao idoso. As médias dos domínios do SF-36 variaram de 77,74\% (capacidade funcional) a 51,29\% (vitalidade). Neste sentido, os resultados obtidos poderão nortear ações estratégicas de qualidade de vida relacionada à saúde para a área da geriatria, na medida em que indicam possíveis associações entre qualidade de vida relacionada à saúde e condição de trabalho, valorização do profissional e organização do trabalho à luz da humanização do atendimento à pessoa idosa.

DESCRITORES: Trabalhador da Saúde; Qualidade de Vida; Saúde da Pessoa Idosa; Ambiente de Trabalho.

\section{ABSTRACT}

The aim of this study was to analyze the quality of life in the work of professionals in the geriatrics sector in a hospital in the city of São Paulo. This is a descriptive, transversal, qualitative study carried out in the Geriatrics sector. The sample consisted of 31 workers (nurses, physicians, nutritionists, speech therapists, Social Worker, psychologists, Administration and Pharmacists) who participated in the study voluntarily, divided into groups. The SF-36 Evaluation Instrument Was applied. The method for analyzing the group was the DSC-Technique that allows analyzing differences and similarities in the vision of collective thinking. The SF-36 domains analyzed were physical functioning, physical and emotional limitation, social functioning, mental health, pain, vitality, and general health perceptions. The results of the DSC analysis made it possible to show that the employees have a positive perception of the various variables related to the dimension of care for the elderly. The averages of the SF-36 domains ranged from $77.74 \%$ (functional capacity) to $51.29 \%$ (vitality). In This sense, the results obtained may guide strategic actions of health-related quality of life for the geriatrics sector, as they indicate possible associations between health-related quality of life and work condition, Appreciation of the Professional and organization of work in the light of the humanization of care for the elderly person. KEYWORDS: Health Worker; Quality of Life; Elderly People's Health; Desktop.

\section{RESUMEN}

El objetivo de este estudio fue analizar la calidad de vida en el trabajo de profesionales geriátricos en un hospital de la ciudad de São Paulo. Este es un estudio descriptivo, transversal y cualitativo realizado en el sector de Geriatría. La muestra consistió en 31 trabajadores (enfermeras, médicos, nutricionistas, logopedas, trabajadores sociales, psicólogos, administración y farmacéuticos) que participaron voluntariamente en el estudio, divididos en grupos. Se aplicó el instrumento de evaluación SF-36. El método para el análisis grupal fue la técnica DSC que permite analizar las diferencias y similitudes de la visión del pensamiento colectivo. Los dominios de SF-36 analizados fueron el funcionamiento físico, la limitación física y emocional, el funcionamiento social, la salud mental, el dolor, la vitalidad y las percepciones generales de salud. Los resultados del análisis DSC permitieron demostrar que los empleados tienen una percepción positiva de las diversas variables relacionadas con la dimensión de la atención a los ancianos. Los dominios SF-36 medios oscilaron entre 77.74\% (capacidad funcional) y 51.29\% (vitalidad). En este sentido, los resultados obtenidos pueden orientar acciones estratégicas relacionadas con la calidad de vida relacionada con la salud para el área geriátrica, ya que indican posibles asociaciones entre la calidad de vida relacionada con la salud y las condiciones de trabajo, la valoración del profesional y la organización del trabajo a nivel geriátrico. a la luz de la humanización de la atención a las personas mayores.

PALABRAS CLAVE: Trabajador de la Salud; Calidad de Vida; Salud de los Ancianos; Ambiente de Trabajo.

RECEBIDO EM: 10/11/2019 APROVADO EM: 11/11/2019 


\section{artigo}

Nascimento, L.H.; Sanches, A.M.; Shirassu, M.; Souza, M.J.L.S.; Carnevalle, C. Waisberg, J.,

Qualidade de vida no trabalho e valorização do profissional do serviço de geriatria em um hospital do município de São Paulo

\section{Luciana Helena do Nascimento}

Especialista. Graduada em Letras pela Universidade Nove de Julho (UNINOVE) e em Biblioteconomia pela Fundação Escola de Sociologia e Política de São Paulo. Especialista em Administração Hoteleira - Faculdades Integradas Hebraico Brasileiras Renascença e em Literatura e Estudos Linguísticos pela UNINOVE.

\section{Ana Maria Sanches}

Médica Sanitarista no Hospital do Servidor Público. Faculdade Bandeirante de Medicina. Doutora em Saúde Pública e Mestre em Epidemiologia pela Universidade de São Paulo. Especialista em Medicina do Trabalho e Administração Hospitalar e de Sistemas de Saúde.

\section{Miriam Shirassu}

Médica do Centro de Promoção e Proteção à Saúde e Coordenadora do Observatório de Promoção da Saúde do Centro de Vigilância Epidemiológica e. Mestre em Epidemiologia pela USP.

\section{Maria José Leonardi Souza}

Biomédica pela Universidade de Santo Amaro. Mestre em Saúde Materno Infantil pela Universidade de Santo Amaro. Doutora em Oncologia pelo AC Camargo (Hospital do Câncer). Coordenadora e Professora da Pós-graduação Lato Sensu em Gerontologia na Universidade Nove de Julho.

\section{Claudia Carnevalle}

Psicóloga, Mestre. pela Faculdade Padre Anchieta. Pós-Graduação em Administração Hospitalar. Mestrado em Saúde Coletiva na Santa Casa de São Paulo.

\section{Jaques Waisberg}

Médico, Coordenador do Programa de Pós-Graduação Stricto Sensu em Ciências da Saúde do Instituto de Assistência Médica do Hospital do Servidor Público Estadual (IAMSPE), Pró-Reitor de Pós-graduação do IAMSPE.

\section{INTRODUÇÃO}

A descoberta e a conquista do trabalho traçaram para a humanidade rumos concretos para a construção da sociedade. Em seus primórdios, a sociedade primitiva era voltada para sobrevivência, bem-estar e desenvolvimento da espécie. Atualmente observa-se uma sociedade difusa, que mescla prosperidade ao bem material, deixando de lado muitas vezes o bem social e cultural, transmitido igualmente através de gerações, tal quais conquistas materiais tecnológicas. As sociedades aprenderam com o trabalho a progredir e criar mecanismos para nos tornarmos a espécie dominante, fosse ele impositivo ou natural ${ }^{(1)}$.

Segundo Rodrigues ${ }^{(2)}$, os estudos relativos à Qualidade de Vida no Trabalho surgiram na Inglaterra em meados da década de 50, por meio do trabalho do sociólogo Eric Trist e seus colaboradores, que realizaram estudos para tentar compreender a relação existente entre indivíduo, trabalho e organização, nos quais observaram que um dos aspectos fundamentais é a realização do indivíduo no trabalho. $\mathrm{O}$ autor esclarece ainda que, somente no início da década de 1970 , o tema foi introduzido publicamente, com a criação dos centros de estudos (Center for Produtivity and Quality of Working Life) nos EUA. Na década de 1990, o tema Qualidade de Vida invadiu todos os espaços, passando a integrar o discurso acadêmico, a literatura relativa ao comportamento nas organizações, os programas de Qualidade Total e a mídia de forma geral.

De acordo com Limongi-França ${ }^{(3)}$, Qualidade de Vida no Trabalho (QVT) é o conjunto das ações de uma empresa que envolvem a implantação de melhorias e inovações gerenciais e tecnológicas no ambiente de trabalho, chama atenção para a amplitude do conceito de qualidade de vida no trabalho. Atualmente não está associado somente à saúde e segurança no trabalho, sinaliza a emergência de conhecimento, habilidade e atitude associados a fatores, como: produtividade, legitimidade, experiências, competências gerenciais, inclusive integração social. A autora afirma ainda que a competência em QVT está associada às questões de saúde, lazer e nutrição, além das habilidades relacionadas à responsabilidade social e relações de trabalho, que são interfaces psicossocial e organizacional.

Para Chiavenato ${ }^{(4)}$, QVT é um conceito que se refere aos aspectos da experiência do trabalho, como estilo de gerência, enquanto, Lessi ${ }^{(1)}$ esclarece que mecanismos de proteção ao trabalho vão além do maquinário, envolvem também a capacidade técnica, cognitiva e emocional do trabalhador, o aproveitamento de suas habilidades, autonomia do uso de suas capacidades, a compreensão do trabalho, envolvendo integração profissional e social dentro da instituição. A eliminação de mecanismos segregadores, como racismo, exclusão de minorias, sexo, entre outros, devem ser considerados, como também, a preservação das relações interpessoais, evitando-se o assédio moral e sexual.

Segundo Marziale e Dantas ${ }^{(5)}$, QVT é a satisfação e o bem-estar do trabalhador durante a execução de sua tarefa. $\mathrm{Na}$ 
maioria das vezes, emprega-se o termo para descrever diversas dimensões básicas da tarefa e outras que não dependem diretamente dela, mas podem motivar e satisfazer em diferentes níveis e visam, sobretudo, melhorar a qualidade dos serviços e a produtividade. Consideram que não há um único conceito sobre qualidade de vida, porém, quando se associa qualidade de vida, bem-estar e a satisfação com os vários aspectos da vida humana, há um certo consenso entre as pessoas. As autoras complementam que a Qualidade de Vida no Trabalho apresenta aspectos que envolvem sentimentos pessoais sobre várias dimensões do trabalho, formas de pensar os indivíduos, a organização do trabalho, o interesse pelo bem-estar dos trabalhadores e a produtividade da empresa.

Porém, é importante ressaltar que para se ter boa qualidade de vida no trabalho, precisamos considerar uma questão primordial que é a saúde, daí a importância de se implantar no trabalho programas de promoção da saúde, que é um processo de conscientização que possibilita uma comunidade atuar para melhorar a qualidade de vida e da saúde, a fim de atingir o bem-estar físico, mental e social de todos. Cabe ressaltar que o documento apresentado na Primeira Conferência Internacional sobre Promoção de Saúde, realizada no Canadá em novembro de 1986 em Ottawa, teve a intenção de contribuir com melhorias das políticas de saúde, onde foi publicada a "Carta de Ottawa" que estabeleceu o marco referencial da promoção da saúde ${ }^{(6)}$.

Existe uma preocupação com a qualidade de vida e o bem-estar no trabalho que está diretamente ligada às condições de trabalho, incluindo o ambiente e a organização do trabalho. Segundo Dejours $^{(7)}$, a organização do trabalho exerce sobre o homem uma ação específica, cujo impacto é o aparelho psíquico.

Ademais, conforme mostra Lefreve ${ }^{(8)}$, o discurso do sujeito coletivo (DSC) que consiste num conjunto de instrumentos destinados a recuperar e dar luz às representações sociais as quais, de modo geral, surgem sob a forma verbal de textos escritos e falados, que são apresentadas sob forma de painéis e depoimentos coletivos e esclarecem que o discurso procura fazer o pensamento coletivo falar de forma direta, o que implica estabelecer um sujeito capaz de incorporar nele o discurso do pensamento coletivo, buscando estender a fala direta para a dimensão subjetiva das representações sociais, que é vista, tradicionalmente como incapaz de se autoexpressar, destinada a ficar na condição de uma terceira pessoa "de quem se fala", daí, a necessidade de um sujeito exterior a ela, para dar a voz aos sujeitos, por exemplo: um pesquisador. O DSC, como técnica de pesquisa empírica que visa o pensamento da coletividade, permite iluminar o campo social pesquisado e possibilita resgatar o universo das diferenças e semelhanças entre as visões dos atores sociais ou sujeitos coletivos do universo que o habitam. A técnica do DSC requer a presença no espaço ou no campo social de sujeitos ou conjuntos de sujeitos a serem entrevistados, de tal modo que os entrevistados vejam sentido no problema investigado e sejam capazes de emitir julgamentos, opiniões e posicionamentos com devidos argumentos. Por isso, é importante, numa pesquisa com a técnica DSC, levar em consideração que os pesquisados se interessem e disponham de informações sobre o problema em questão.

Nesse sentido, em certas condições, emerge um sofrimento que pode ser atribuído ao choque entre uma história individual, portadora de projetos, de esperanças e de desejos e uma organização do trabalho que os ignora. Nesse sentido, avaliar a qualidade de vida no serviço de Geriatria é um tema que exige profunda reflexão, pois tem como atividade principal a de prestar serviços para melhorar a vida de idosos que requerem cuidados especiais. A pesquisa teve como objetivo utilizar da aplicação do SF-36(9) e do DSC para analisar a qualidade de vida no trabalho dos profissionais do setor de Geriatria em um hospital no município de São Paulo e descrever os fatores que influenciam a qualidade de vida.

\section{METODOLOGIA}

Trata-se de estudo descritivo, transversal, qualitativo, realizado no setor de Geriatria do Hospital do Servidor Público Estadual de São Paulo. O setor de Geriatria do hospital em estudo tem como missão melhorar a qualidade de vida dos contribuintes e beneficiários do Instituto de Assistência Médica ao Servidor Público Estadual de São Paulo (Iamspe) por meio da promoção, prevenção e reabilitação da saúde, com apoio contínuo ao ensino e pesquisa. O estudo foi aprovado no Comitê de Ética em Pesquisa do Iamspe sob o parecer n. ${ }^{\circ} 1.067 .713$.

Foram incluídos no estudo 31 trabalhadores de um total de 57, que assinaram o Termo de Consentimento Livre e Esclarecido (TCLE), em duas vias, sendo que uma cópia ficou em posse da pesquisadora e outra com o participante, conforme as regulamentações do Conselho Nacional de Ética em Pesquisa nas funções de enfermeiros, médicos, nutricionistas, fonoaudiólogos, assistentes sociais, psicólogos, administração e farmacêuticos, com idades entre 23 a 63 anos, residentes em São Paulo. A pesquisa foi realizada no próprio hospital nos meses de julho e agosto de 2015. Os trabalhadores participaram de forma voluntária, responderam o The Medical Outcomes Study 36- item Short-Form Health Survey (SF-36), e participaram dos grupos focais para a realização da análise do discurso do sujeito coletivo (DSC).

O DSC é uma técnica de pesquisa qualitativa que permite analisar as diferenças e semelhanças da visão do pensamento coletivo em um determinado ambiente. Os 31 participantes aceitaram fazer parte do estudo conforme foi esclarecido a cada participante do estudo que a privacidade e anonimato seriam assegurados durante a entrevista. Não participaram da pesquisa funcionários que não faziam parte do setor de Geriatria e aqueles que, mesmo sendo da área, por motivos particulares não quiseram participar.

Foram criados três grupos focais, distribuídos em dez, nove e sete parti- 


\section{artigo}

Nascimento, L.H.; Sanches, A.M.; Shirassu, M.; Souza, M.J.L.S.; Carnevalle, C. Waisberg, J.

Qualidade de vida no trabalho e valorização do profissional do serviço de geriatria em um hospital do município de São Paulo

cipantes, respectivamente. Os grupos foram orientados de forma a construir debates dinâmicos, com base no roteiro pré-definido de perguntas voltadas para as funções do setor de Geriatria, assegurando aos participantes agir de maneira flexível ao discutirem os assuntos vinculados ao roteiro, à medida que foram sendo abordados. Foram analisadas as falas, gestos de cada participante individualmente e coletivamente e o clima relacional do grupo. O relatório produzido constante deste documento corresponde às gravações dos grupos focais, as quais foram analisadas e comparadas para obter uma visão geral sobre os temas discutidos em comum.

Ao final, o moderador constrói um relatório contendo todo o material audiovisual e textual gerado na discussão e um resumo dos comentários mais importantes, além de acrescentar suas conclusões e recomendações, dado o caráter subjetivo da pesquisa qualitativa e do envolvimento dos representantes. O moderador é a pessoa mais indicada para exprimir o que realmente se passou durante a discussão do grupo focal.

A análise dos dados coletados foi com base na técnica do DSC que, operacionalmente, segue os seguintes passos: expressões-chave de cada discurso individualmente, as quais se constituem em segmentos contínuos ou descontínuos do discurso e revelam o principal do conteúdo discursivo; identificação da ideia central de cada uma dessas expressões-chave, ou seja, o que os participantes querem efetivamente expressar; identificação das ideias semelhantes ou complementares.

O SF-36 é um instrumento genérico de avaliação da qualidade de vida, de fácil administração e compreensão. É um questionário multidimensional formado por 36 itens englobados em oito escalas ou domínios, que são: capacidade funcional, aspectos físicos, dor, estado geral de saúde, vitalidade, aspectos sociais, aspectos emocionais e saúde mental. Esse instrumento é bem desenhado e suas propriedades de medida, como reprodutibilidade, qualidade e suscetibilidade a alterações já foram bem demonstradas em diversos trabalhos. O questionário foi aplicado numa investigação no âmbito de uma dissertação de mestrado sobre a saúde dos funcionários do setor de Geriatria.

\section{RESULTADOS}

Os dados apurados no QSD (Questionário Sócio Demográfico), as médias dos domínios dos instrumentos The Medical Outcomes Study 36 - item Short-Form Health Survey (SF-36), seguidos da análise comparativa dos resultados do Discurso do Sujeito Coletivo com o referencial teórico, estão escritos abaixo. Os dados apurados referem-se a 31 participantes que responderam o FS-36 e do Discurso do Sujeito Coletivo.
O Quadro 1 revelou que a maioria dos profissionais (pesquisados) do setor de geriatria foram mulheres (84\%) com faixa etária entre 30 a 39 anos (42\%), assim como identificou que a maioria tem até 10 anos de exercício na função. No quesito capacitação patrocinado pelo Hospital para cuidar de idosos: 20 $(64,52 \%)$ responderam que possuem tal capacitação, 11 (35,48\%) disseram que não possuem. Quanto à capacitação realizada em outra entidade: $14(45,16 \%)$ responderam que se capacitaram em outro local, 17 (54,84\%) responderam que não. Quanto à valorização no ambiente de trabalho, independente do cargo ou função: 19 (61,29\%) responderam que se sentem valorizados e $11(35,48 \%)$ disseram que não se sentem valorizados. 1 $(3,23 \%)$ não respondeu.

\section{Quadro 1. Perfil dos Profissionais do setor de geriatria do Hospital geral do} Servidor Público Estadual, referente ao SF-36. São Paulo, SP, Brasil, 2015

\begin{tabular}{|c|c|c|c|}
\hline \multicolumn{2}{|c|}{ VARIÁVEIS } & \multirow[t]{2}{*}{$\mathbf{N}$} & \multirow[t]{2}{*}{ PERCENTUAL } \\
\hline Gênero & & & \\
\hline onturo & Feminino & 26 & $84 \%$ \\
\hline & Masculino & 5 & $16 \%$ \\
\hline \multirow{5}{*}{ Idade } & $20-29$ & 6 & $19 \%$ \\
\hline & $30-39$ & 13 & $42 \%$ \\
\hline & $40-49$ & 4 & $13 \%$ \\
\hline & $50-59$ & 6 & $19 \%$ \\
\hline & Acima de 60 anos & 2 & $6 \%$ \\
\hline \multirow{7}{*}{ Tempo de exercício na função } & Até 5 anos & 13 & $42 \%$ \\
\hline & 6-10 anos & 4 & $13 \%$ \\
\hline & 11-15 anos & 3 & $10 \%$ \\
\hline & $16-20$ anos & 4 & $13 \%$ \\
\hline & 21-30 anos & 4 & $13 \%$ \\
\hline & Acima de 30 anos & 1 & $3 \%$ \\
\hline & Sem informação & 2 & $6 \%$ \\
\hline \multirow{4}{*}{ Regime trabalhista } & CLT & 17 & $55 \%$ \\
\hline & Estatutário & 12 & $39 \%$ \\
\hline & Terceirizada & 1 & $3 \%$ \\
\hline & Estagiário & 1 & $3 \%$ \\
\hline \multirow{3}{*}{ Capacitação no lamspe } & Sim & 20 & $44 \%$ \\
\hline & Não & 11 & $24 \%$ \\
\hline & Capacitação externa & 14 & $31 \%$ \\
\hline
\end{tabular}


Os dados apresentados no Quadro 2 mostrou que os profissionais possuem um bom estado geral de saúde. Tendo em vista que $50 \%$ é o escore médio, conforme o que apresenta o SF-36. Na pesquisa observou que os itens do SF-36 estão acima da média. de interfere: o sono, não a falta dele porque eu tenho muito, o problema é que eu não consigo dormir [...] a gente dava conta de quase todos os locais, como ela mesma falou, a questão do salário... a gente perdeu muitos dos nossos profissionais por conta

\begin{tabular}{|c|c|c|}
\hline DOMíNIO & $\mathbf{N}$ & MÉDIA SCORE \\
\hline Capacidade Funcional & 31 & 77,74 \\
\hline Aspectos Físicos & 31 & 63,7 \\
\hline Dor & 31 & 61,83 \\
\hline Estado Geral da Saúde & 31 & 54,41 \\
\hline Vitalidade & 31 & 51,29 \\
\hline Aspectos Sociais & 31 & 71,45 \\
\hline Aspectos Emocionais & 31 & 66,66 \\
\hline Saúde Mental & 31 & 68,9 \\
\hline
\end{tabular}

O DSC, cujo objetivo central é identificar sentimentos, percepções, atitudes e ideias dos participantes a respeito de determinado assunto, estão apresentados nos quadros abaixo. Os resultados foram tabulados e feita a análise do discurso das práticas do sujeito coletivo, levando-se em consideração as divergências e convergências e a subjetividade que há nos mesmos, confrontando-os com o referencial teórico. Questóes propostas e as respectivas ideias centrais estão apontadas nos quadros abaixo:

1. Como vocês avaliam sua saúde hoje?

Ideia Central: Saúde comprometida pelas condições e sobrecarga de trabalho e salário

Vem constantemente sendo agravada pelas condições de trabalho que nós temos aqui. Um volume muito grande de atendimento em condições muito precárias, com poucos funcionários [...]. Porque tem uma hora que o seu corpo fala... O corpo grita e fala "pelo amor de Deus para um pouco"! Demanda cada vez mais crescente, pressão dos idosos por acolhimento, pressão dos idosos por tratamento melhor [...] por estresse, por cansaço... [...] Tá bem cansativo! Mas o que dificultou [...] e que hoje na saú- disso. [...] obriga-se a fazer o plantão porque senão você não tem uma renda.

Idéia Central: Saúde física adequada e a satisfação pelo atendimento ao idoso

A minha saúde, graças a Deus, eu estou bem, [...] Saúde física eu acho que tudo bem porque nada gritou e eu também não fui ao médico. Se é para sacrificar alguém que sacrifique a gente né. Porque o paciente já idoso se desloca de longe, sua consulta está marcada com mais outros três pacientes. Então é melhor sacrificar a gente nesse momento do que sacrificar o paciente. E o paciente não tem culpa disso tudo? Então a gente faz o máximo que pode para conseguir atender bem e num tempo hábil. Aqui na geriatria também tem a questão do psicológico, do cuidador, aquele que está com o idoso, que a gente tem que trabalhar bastante. Mas a gente tem trabalhado naquele projeto que a gente tem "Integralidade" que orienta e que dá curso. A gente se doa, a gente entende que nós somos da saúde, o paciente em primeiro lugar. Aqui na geriatria, além de nós de enfermagem fazermos a nossa profissão, cuidar do paciente, a gente também tem de cuidar do emocional da família. Às vezes você acaba cuidando dos dois, dando aten- ção para o paciente e cuidando da família emocionalmente. Os pacientes todos dependem da gente. Não tenho problema de fazer o que gosto.

2. Como é que vocês estão vendo a qualidade de vida no trabalho?

Ideia Central: A qualidade de vida no trabalho relacionada com a questão da condição de trabalho

Eu acho que depende do setor, essa parte eu acho que é bem diversificada porque lá na psicologia se for comparar quando a gente andou há 12 anos como agora, nós estamos no Primeiro Mundo. Nós temos computador na sala, está supertranquilo. Tem a secretária que faz o agendamento. Nós também podemos fazer o agendamento de dentro da sala, imprimir a folha... Isso está a anos-luz do que nós vimos há anos atrás. Mas é isso, esse tipo de coisa não chegou a todos os setores. Tem cama no hospital inteiro, pra gente não tem cama nova, só tem as mais antigas que não abaixam, que não dá pra gente levar o paciente pro chuveiro. Pra gente conseguir estimular o paciente, nada favorece. A gente tem o esforço físico... o esforço na coluna. A gente tem muitos funcionários com problemas na coluna que estão afastados por conta disso. Então, na falta deles quem é sobrecarregado somos nós. A questão dos equipamentos - precisamos muito".

Ideia Central: Qualidade de vida no trabalho comprometida por conta dos conflitos, trabalho desgastante, falta de incentivo, cobrança, falta de valorização, sobrecarga de trabalho.

Valorização, da pressão, de cobranças, tanto da chefia quanto pelo trabalho... funcionários ficam sobrecarregados pra executar, tudo isso gera um desgaste e gera uma piora na qualidade de vida aqui dentro. Principalmente a gente não consegue ter um tempo de descanso que a gente consiga descontrair. Você está constantemente lidando com conflitos familiares. A motivação, eu acho que é mais importante do que os recursos humanos, se você não tem um funcionário motivado, então ele não 


\section{artigo}

Nascimento, L.H.; Sanches, A.M.; Shirassu, M.; Souza, M.J.L.S.; Carnevalle, C. Waisberg, J.,

Qualidade de vida no trabalho e valorização do profissional do serviço de geriatria em um hospital do município de São Paulo

fica. Precisamos ter algum incentivo para melhorar. Eu acho que é a grande diferença para uma empresa privada, quando você tem uma escassez de recursos humanos, a pessoa consegue puxar essas pessoas, então eu vou contratar um funcionário temporário pra substituir aquela pessoa. Aqui se alguém não está naquele dia pra fazer aquela função, os outros funcionários ficam sobrecarregados pra executar aquilo. Eles teriam que dar condições boas de trabalho pros próprios funcionários dar o retorno. Percebo que é o trabalho desgastante, porque quando saio de férias tudo melhora. Precisamos ter algum incentivo para melhorar aqui, não sei dizer o que pode fazer para melhorar, mas precisa mudar alguma coisa.

Ideia Central: Realização profissional e satisfação diferenciada da qualidade de vida no trabalho por cuidar de idosos.

Para mim é um prazer trabalhar no que gosto, lidar com pessoas, lidar com idosos, então o peso do cansaço fica menor. A minha qualidade de vida aqui na geriatria? A vida é dura, mas algumas pessoas tornam a vida mais pesada. Temos que mudar também, tentar fazer a vida mais leve. Talvez a minha qualidade de vida pode melhorar, mas tenho que mudar também os meus hábitos. Eu acho que é a gratidão que eles têm com a gente. Muitas vezes nós fazemos a nossa obrigação e eles ficam muito agradecidos. É aquela coisa de trazer o conforto para quem está com sofrimento, é bem gratificante. Mesmo para os acompanhantes porque as jornadas deles são tão difíceis[...] o que é um simples sorriso, um pouco de conforto para eles, ficam super felizes. Eles entendem também e sabem que você está fazendo o máximo por eles. É bem gratificante quando eles têm alta e olham pra você e dizem "Muito obrigado por tudo. Você tratou muito bem a minha avó, a minha mãe... muito obrigado mesmo!". E é bem legal isso, a gente se sente bem legal com isso. É bem gratificante quando eles têm alta e olham pra você e dizem "Muito obrigado por tudo. Eu acho que o sofrimento maior que tenho visto é a saída dos profissionais. Eu particularmente, estou muito feliz com o meu tra- balho aqui, eu gosto e tenho vínculo aqui. $\mathrm{Eu}$ acho que é o atendimento melhor ao idoso. Eu digo isso porque meus pais estiveram na geriatria e os dois foram muito bem atendidos pelos médicos da geriatria. E hoje a gente tem visto [...] idosos que não casaram, não tem amigos, irmãos faleceram, então não tem nenhuma rede de amigos que eles possam contar e o hospital acaba fazendo esse papel.

3. Como é a relação de vocês entre a chefia e companheiros de trabalho?

Ideia Central: Integração da equipe e formação multiprofissional na contribuição da qualidade de vida no trabalho

Aqui na geriatria... aqui é interdisciplinar, então assim, a gente sente que há o respeito entre os profissionais. A geriatria conseguiu ter o maior número de profissionais: tem assistente social, hoje não tem psicólogo, mas até dois anos atrás tinha psicólogo, não teve assistente social ano passado, mas esse ano já tem. Então tem fases de mudanças, mas eu acho que é o único setor do hospital que consegue manter uma equipe dentro do setor. A relação não tem problema, pelo contrário, os médicos são muito bons e os companheiros também. Eu acho que dá para fazer um trabalho de qualidade, dá pra fazer interdisciplinar e multiprofissional. [...]. E a maior parte das pessoas que estão envolvidas, por exemplo, especialistas da área de gerontologia estão muito ligados porque trabalham em outros lugares. A gente acaba acumulando funções que nem sempre são as nossas. A gente passou por uma parte conflituosa quando juntaram as duas enfermarias porque aqui [...] porque muitos não pensavam do mesmo jeito, não caminhavam do mesmo jeito então... a equipe não estava acostumada com o tipo de paciente que a gente trouxe, eles tinham pacientes da geriatria aqui, mas eles não estavam acostumados com o número de pacientes. Mas isso melhorou muito. Foi uma fase de adaptação mesmo. Mas no geral, as equipes de fisioterapia, fonoaudiologia, nutrição, enfermagem, e mesmo a equipe médica, a gente procura trabalhar junto".

Ideia Central: A importância da valorização da chefia e o perfil do paciente na contri- buição da qualidade de vida no trabalho

A chefia que é excepcional nos dá apoio e que nos incentiva. Mas eu acho que a geriatria tem um perfil diferenciado mesmo porque é direto com os idosos. A equipe de geriatria é muito legal, todo mundo se dá muito bem, se ajudam, mas tem muita coisa que nos prejudica muito. Mas mesmo assim a equipe se dá bem. Não tem problema com a chefia, eles escutam, querem saber como estão as coisas, querem opinião, sugestão, mas infelizmente não podem fazer muita coisa. O pessoal é bem camarada mesmo e a gente fica contente que a pessoa tenha conseguido a alguma coisa melhor. Eu acho que é a gerontologia tem essa proposta de ensino, e aqui de aprimoramento já deve ter uns 16 anos, tem a residência... Então eu acho que durante esse tempo foi construído todo um trabalho.

\section{DISCUSSÃO}

A qualidade de vida no trabalho é um tema contemporâneo necessário e, quando analisado nos ambientes em que o trabalho está relacionado ao atendimento com idoso, ainda torna-se mais complexo, conforme mostra esse estudo e que é corroborado por vários autores que apontam que a qualidade de vida no trabalho dos profissionais da área de saúde causam diversos problemas tanto físicos e psicológicos e comprometem a saúde dos profissionais, especificamente em relação a problemas físicos.

Os dados do estudo revelaram uma amostra constituída de indivíduos em idade potencialmente produtiva; é relevante ressaltar que os profissionais têm em mente que a essência do seu trabalho é o bom atendimento e atender bem os idosos é primordial. Assim, corroborando com Dejours ${ }^{(7)}$, o "[...] tema qualidade de vida, engloba estado físico e habilidades funcionais, estado psicológico e bem-estar, interações sociais e tantos outros aspectos que levam o indivíduo a interagir com o mundo".

Apesar dos resultados serem focados nos aspectos da qualidade de vida relacionados à saúde dos profissionais de Geriatria, outras áreas do hospital também foram citadas, o que pode identificar é que 
algumas áreas estão muito bem equipadas, principalmente quando se compara com a situação do passado. Porém, em outras áreas, fatores relacionados à ergonomia e suas consequências sobre a saúde ocupacional foram os mais citados como comprometedores da qualidade de vida no trabalho.

Nesse sentido, Rodrigues ${ }^{(2)}$ aborda estudos do sociólogo Eric Trist para tentar compreender a relação existente entre indivíduo, trabalho e organização, sua equipe observou que um dos aspectos fundamentais é a realização do indivíduo no trabalho.

Um dos fatores que afeta, de sobremaneira, as condições de saúde é a demanda cada vez maior do atendimento aos idosos devido ao envelhecimento da população usuária do hospital. A sobrecarga de trabalho tem, entre outras causas, a falta de funcionários que se demitem em busca de salários melhores, seja no setor público ou privado. De modo geral, observa-se pelo DSC que são os profissionais mais novos que buscam outras oportunidades, enquanto os mais antigos buscam por meio de plantões com melhor remuneração. Situação que lhes proporcionou melhores rendimentos, mas, por outro lado, pode interferir nas condições de saúde desses trabalhadores.

Contudo, ficou claro que os problemas levantados não interferem no bom atendimento ao idoso. Embora o trabalho seja cansativo, revela um DSC com avaliação positiva, sem interferência direta na saúde física. Os trabalhadores procuram sempre atender bem e com afetividade e respeito aos idosos, porque são conscientes que as dificuldades no ambiente de trabalho não devem interferir no atendimento aos pacientes idosos. O setor de Geriatria conta com profissionais especializados, o que contribui para melhorar o atendimento aos idosos. Esse discurso corrobora com a afirmação dos autores Amaral et al. ${ }^{(11)}$ no artigo "Qualidade de vida no trabalho dos profissionais de enfermagem em ambiente hospitalar".

Outra questão que aponta o discurso é que vem sendo exigido do profissional de saúde que cuida de idosos, novas habilidades e competências à medida que a população está envelhecendo, como bem observa Kalache ${ }^{(10)}$.

Na ótica do economista Freeman apud por Couto ${ }^{(11)}$, a satisfação no trabalho se prende essencialmente como um problema de salários, eficiência e indicadores macro e microeconômicos". Entretanto, pôde-se constatar neste $\mathrm{DSC}^{(8)}$, que o reconhecimento do trabalho, tanto pelos colegas de mesma hierarquia e de hierarquia superior e, principalmente, pelos pacientes atendidos, traz muita satisfação para aqueles que prestam serviço de atendimento.

[...]

A sobrecarga de

trabalho tem,

\section{entre outras}

causas, a falta de

funcionários que

se demitem em

busca de salários

melhores, seja no

setor público ou

privado.

$\mathrm{Na}$ ideia central em que se discutiu, a saúde física adequada e a satisfação pelo atendimento ao idoso, pôde-se identificar no $\operatorname{DSC}^{(8)}$ que um dos fatores que comprometeu a qualidade de vida no trabalho é a pressão da chefia pelo cumprimento das atividades que, na maioria dos casos, é sobrecarregado por escassez de recursos humanos. Ressalta-se para que esta questão em $\mathrm{DSC}^{(1)}$ é reveladora a respeito da realização profissional e do nível de satisfação nos serviços prestados pelos funcionários. Apesar dos vários apontamentos dos participantes em relação ao desgaste físico e mental, sobrecarga de trabalho, stress e tantos outros fatores, tudo isso é minimizado pelo respeito, gratidão e carinho que os idosos, familiares e cuidadores demonstram aos profissionais. Pelos relatos, o que contribui para os funcionários, de forma significativa, e torna o trabalho mais "suave” e gratificante é a qualidade das relações interpessoais com os idosos, com o reconhecimento dos mesmos pelos serviços e disponibilidade de equipe multiprofissional especializada no tema ${ }^{(5,8,11,12)}$.

Neste sentido, o DSC possibilita evidenciar que os funcionários possuem uma percepção positiva das diversas variáveis relacionadas à dimensão do atendimento ao idoso. Isto remete a uma concepção mais ampla da qualidade de vida no trabalho. Em se tratando de serviço de saúde, em especial aos cuidados no atendimento ao idoso, as relações interpessoais estabelecidas no processo de atendimento demonstram significativos resultados na qualidade de vida, relacionada à saúde do trabalhador, que vão além daqueles conquistados por meio de procedimentos e protocolos, exigidos por normas ou legislações

\section{CONCLUSÃO}

A qualidade de vida no trabalho dos funcionários relacionada à saúde do setor de Geriatria, segundo resultados do SF36, bem como das respostas dos participantes analisadas por meio do Discurso do Sujeito Coletivo, está adequada tendo em vista a organização do trabalho; o relacionamento interpessoal da equipe e, especificamente, quanto ao trabalho com os idosos os quais lhes permitem momentos únicos de convivência, aprendizado e respeito ao trabalho que realizam.

No entanto, destacam-se outras variáveis que devem ser observadas com vistas à qualidade de vida no trabalho, tais como: a revisão de processos de trabalho, a ressignificação do trabalho, a apropriação das tarefas e a gestão participativa e interdisciplinar. 


\section{artigo}

Nascimento, L.H.; Sanches, A.M.; Shirassu, M.; Souza, M.J.L.S.; Carnevalle, C. Waisberg,

Qualidade de vida no trabalho e valorização do profissional do serviço de geriatria em um hospital do município de São Paulo

Nesse sentido, os resultados obtidos podem nortear ações estratégicas de Qualidade de Vida Relacionado à Saúde (QVRS) para a área da Geriatria, na medida em que indica possíveis associações entre a QVRS como condição de trabalho, valorização do profissional e organização do trabalho à luz da humanização do atendimento à pessoa idosa. Além disso, é fundamental a realização de novos estudos bem como a discussão de práticas que requeiram tecnologias leves específicas a respeito da relação dos profissionais e clientes idosos para o aprimoramento da qualidade do atendimento, bem como garantir a qualidade de vida no trabalho dos envolvidos.

Com destaque ao Discurso do Sujeito Coletivo, observa-se a valorização dos profissionais pela chefia e o perfil do paciente contribui na qualidade de vida. A relação interpessoal entre a chefia e companheiros de trabalho demonstra ser muito boa, independentemente do cargo ou função exercida pelo funcionário. Contudo, a escassez de funcionários provoca a sobrecarga de trabalho, tendo como consequência a pressão da chefia para cumprimento das atividades. Fica evidenciado no Discurso do Sujeito Coletivo que o perfil diferenciado com relação à integração efetiva dos funcionários está diretamente relacionado à qualidade das relações interpessoais com idosos. Some-se a isso, o fato de a área de Geriatria ter uma equipe multiprofissional e ensino voltados ao aprimoramento, promovendo uma maior especialização nos cuidados dos idosos.

O método do Discurso do Sujeito Coletivo possibilitou organizar e tabular os dados coletados, qualiquantitativos de natureza verbal, obtidos por depoimentos.
Portanto, pode-se afirmar que essa boa relação possibilita desenvolver um trabalho de qualidade, interdisciplinar e multiprofissional, o que contribui significativamente para o ambiente salutar e, consequentemente, para uma boa qualidade de vida relacionado à saúde do trabalhador. -

\section{Agradecimentos}

Agradeço ao meu orientador, Prof ${ }^{\circ}$ Dr. Jaques Waisberg, à co-orientadora Profa Dra. Ana Maria Sanches e às colaboradoras Profa Dra. Mirian Shiarassu a Profa Me Cláudia Carnevalle pelo apoio e encorajamento que me deram ao transcorrer do curso e a Profa. Dra. Maria José Leonardi no incentivo aos estudos e pesquisas na área.

Agradeço ainda ao meu grande amigo e querido Profo. Me Erledes Elias da Silveira por todo apoio no caminhar desses anos.

Por fim, agradeço ao colegiado do IAMSPE pelo apoio institucional.

\section{REFERÊNCIAS}

1. Lessil SL. Assédio Moral. O Moderno Tripalliun do Trabalho [Internet]. Ceaesp - Centro Avançado de Estudos na Gestão Pública [acesso em 07 dez 2016]. Disponivel em: http://www. sindicatouniao.org.br/pdf/assedio_moral.pdf.

2. Rodrigues CAL. Perfil dos cuidadores formais de idosos e motivos para a função: um estudo de caso. Dissertação (Mestrado em Gestão das Organizações, Ramo de Gestão de Empresas) - Instituto Politécnico de Viana do Castelo, Viana do Castelo [Internet]. 2014 [acesso em 22 abr 2018]. 87f. Disponível em: http://repositorio.ipvc.pt/bitstream/123456789/1141/1/Catarina_Rodrigues.pdf.

3. Limongi-Franca AC. Qualidade de vida no trabalho - QVT: conceitos e práticas nas empresas da sociedade pós-industrial. São Paulo: Atlas S. A.; 2009. p. 09.

4. Chiavenato I. Gestão de pessoas: o novo papel dos recursos humanos nas organizações. 14. ed. Rio de Janeiro: Campus; 1999, p. 09.

5. Marziale MHP, Dantas RA. Qualidade de vida no trabalho. Saúde e segurança em serviços de saúde. In: HARADA, Maria de Jesus C. S. (Org.). Revista Gestão de Enfermagem: ferramenta para prática segura. Gestão de enfermagem. São Caetano do Sul: Yendis Editora; 2011. p. 455- 461.

6. Andrade EA, André LM, Westphal MF. Avaliação de Projetos na lógica da promoção da saúde na Secretaria de Estado da Saúde de So Paulo - CAP. 01 - Promoção da Saúde: desenvolvimento e princípios - 1. ed. - São Paulo: Hucitec: Cepedoc Cidades Saudáveis, 2014.

7. Dejours C. A Loucura no Trabalho: Estudo de Psicopatologia do Trabalho. Trad. de Ana Isabel Paraguay e Lúcia Leal Ferreira. São Paulo: Cortez - Oboré; 1992. 168p. Dejours C. L'ergonomie en quête de ses principes. Dèbats Épistémologiques. Em, F. Daniellou (Org), Épistémologie concrète et ergonomie, (p.201-217) Paris: Octares Edition. Travail, usure mental: de la psychopatologie du travail à la psychodynamique du travail. ed. ampliada. Paris: Bayard; 1993.

8.Lefreve F, Lefreve AMC. Pesquisa de representação social: um enfoque qualiquantitativo: a metodologia do discurso do sujeito coletivo. 2. ed. Brasilia: Liberlivro; 2012. v. 1000. 224p.

9. Ciconelli RM, Ferraz MB, Santos W, Meinão I, Quaresma MR. Revista Brasileira de Reumatologia [Internet]. 1999 [acesso em 22 abr 2016]; 39(3). Disponivel em: http://bases.bireme.br/cgibin/wxislind.exe/iah/online.

10.Kalache A. Gerontolescência [Internet]. Por Lina Menezes, em Reflexões. 2013 [acesso em 10 dez 2019]. Disponivel em: http://fazmuito bem.com/alexandre-kalache-gerontolescencia.

11. Couto MJBLF. Autoeficácia e satisfação no trabalho em Técnicos de Diagnóstico e Terapêutica. Dissertação (Mestrado em Gestão das Organizações, Ramo de Gestão de Empresas) Instituto Superior de Contabilidade e Administração do Porto, Portugal [Internet]. 2012 [acesso em 19 fev 2016]. 59 f. Disponivel em: http://recipp.ipp.pt/bitstream/10400.22/3102/1/ DM_MariaCouto_2012.pdf.

12.. Amaral JF, Ribeiro JP, Paixão DX. Qualidade de vida e satisfação no trabalho dos profissionais de enfermagem em ambiente hospitalar: uma revisão integrativa. Revista Espaço para a Saúde. 2015 jan./mar.; 16(1): 66-74. 